\title{
Reflexiones en torno a los desafíos éticos en el trabajo en equipo interdisciplinario
}

\author{
Reflections on the ethical challenges in interdisciplinary \\ teamwork
}

Reflexões em torno dos desafios éticos no trabalho em equipe interdisciplinar

Paola Zárate Flores*

\section{RESUMEN}

El artículo tiene como propósito reflexionar acerca de los desafíos éticos del Trabajo en Equipo Interdisciplinario (TEI), a partir de una experiencia de diálogo en torno al tema con estudiantes de posgrado.

Además, mencionar la relevancia que posee la perspectiva ética, siempre presente en el abordaje de la complejidad de lo real, junto a aquella dimensión institucional y contextual desde la que se sitúa hoy el trabajo en equipo. Se enuncian aportaciones de diversos autores, quiénes, desde sus particulares contribuciones, reflexionan en torno a la necesidad de ir generando nuevas formas de comprensión e interpretación de los desafíos éticos, en cuanto dilemas que nos plantea la praxis, por medio del reconocimiento de múltiples aspectos que influencian el quehacer, facilitando o tensionando procesos de deliberación colectiva para arribar a acuerdos comunes.

\section{SUMMARY}

The purpose of this article is to reflect on the ethical challenges of Interdisciplinary Teamwork, based on dialogue on the subject with graduate students.
Palabras clave: desafíos éticos, Trabajo en Equipo Interdisciplinario, perspectiva ética, praxis.

Key words: ethical challenges, Interdisciplinary

* Chilena. Asistente Social. Magíster Etica Social y Desarrollo Humano. Asistente Social ONG Paicabi. Docente Carrera de Trabajo Social. Universidad Viña del Mar (UVM). E-Mail: zarate.paola6@gmail.com 
In addition, it is worth mentioning the relevance of the ethical perspective, always present in the approach to the complexity of reality, together with the institutional and contextual dimension from which teamwork is situated today. We present contributions from various authors, who reflect on the need to generate new ways of understanding and interpreting the ethical challenges posed by praxis through recognizing multiple aspects that influence the work, facilitating or stressing processes of collective deliberation to reach common agreements.

\section{RESUMO}

O artigo tem o propósito de refletir sobre os desafios éticos do Trabalho em Equipe Interdisciplinar (TEI), a partir de uma experiência de diálogo em torno do assunto com estudantes de pósgraduação.

Além disso, mencionar a relevância da perspectiva ética, sempre presente na abordagem da complexidade do real, junto com aquela dimensão institucional e contextual desde a qual se situa hoje o trabalho em equipe. São apresentadas contribuições de diversos autores, os quais, desde suas particulares colaborações, refletem em torno da necessidade de gerar novas formas de compreensão e interpretação dos desafios éticos, em relação a dilemas que nos apresenta a práxis, por meio do reconhecimento de múltiplos aspectos que influenciam a atividade, facilitando ou tensionando processos de deliberação coletiva para chegar a acordos comuns.
Teamwork, ethical perspective, praxis.

Palavraschave: desafios éticos, trabalho em equipe interdisciplinar, perspectiva ética, práxis. 


\section{Introducción}

Para introducir el tema, se analizan aquellos desafíos éticos presentes en el Trabajo en Equipo Interdisciplinario (TEI) asociados particularmente a la praxis de aquellos profesionales que laboran en el área psico-socio-judicial -psicólogos, trabajadores sociales, abogados, profesores, entre otros- - . Cabe señalar que este trabajo ha sido posible gracias al diálogo y reflexiones desarrolladas con estudiantes de posgrado durante las clases del Módulo de Ética y Liderazgo ${ }^{1}$, en el cual tuve la oportunidad de participar durante el primer semestre de 2020. Tales reflexiones se producen en el momento en que toda la institucionalidad se ha visto puesta a prueba por la crisis social que ha afectado a Chile desde octubre de 2019, sumado a la pandemia de coronavirus en 2020. Por lo anterior, hacer referencia a los desafíos éticos del trabajo en equipo interdisciplinario cobra especial relevancia en este contexto, ya que se trataría de un necesario y urgente llamado a revisar y repensar nuestra praxis interdisciplinar, así como a desplegar esfuerzos para generar y poner en práctica estrategias y acciones que impacten en forma positiva al colectivo social. En este escenario, la ética, en cuanto filosofía primera ${ }^{2}$, emerge como posibilidad para promover la reflexividad del quehacer profesional.

Para los efectos del presente artículo se intentará, por medio de una serie de consideraciones, establecer una relación entre el mundo de las ideas y la praxis, de manera de analizar los distintos aspectos que influencian las prácticas de actuación interdisciplinar.

En el actual contexto y contingencia social, surge cada vez con mayor fuerza la necesidad de contar con un marco ético que promueva la deliberación colectiva de aquellos desafíos con los cuales usualmente nos encontramos en el trabajo en equipo, y que se vincularían al área de resolución de problemas, asociada a nuestro quehacer profesional y a factores contextuales que poseen un impacto ineludible en el tema.

Los desafíos que se presentan en la praxis tendrían una dimensión teleológica, entendiendo la palabra "teleología" desde una perspectiva

1 Magíster en Intervenciones Psicosociojurídicas en el Ámbito Penal y de Familia, UVM.

2 Afirmación propuesta por el filósofo lituano Emmanuel Levinas y que fundamenta en su libro Totalidad e Infinito (2002). 
levinasiana, como una especie de disposición hacia el infinito, asimismo como tratamiento de una vida consciente esencialmente teleológica (Martínez, 2020). Tal disposición de la conciencia interrogaría a los equipos en forma permanente sobre cuáles son los fines o resultados que pretenden alcanzar, así también respecto de la orientación de sentido que subyace a la consecución de dichos fines. Acontecería que usualmente nos encontramos con el nudo crítico representado por el problema de la parcelación disciplinaria, pese a ello, algunas voces declaran que estamos en un importante momento de cambio en la formación y el ejercicio de las disciplinas, ya que en el presente habría una explosión en las formas de diferenciación e integración, siendo necesario, a nivel de formación, preparar a los egresados para enfrentar los desafíos actuales por medio del establecimiento de vínculos y nuevas formas de trabajo (Hernández y López, 2002). En este aspecto, los autores hacen referencia a una necesidad presente en la formación de estudiantes en educación superior.

Acerca de la importancia de la interdisciplinariedad en contextos educativos, Rodríguez, Carranza, Bulgarelli, Ulate y Camacho (2020) se refieren a lo siguiente:

Cabe destacar que la interdisciplinariedad evita el desarrollo o ejecución de trabajos fragmentados por áreas del saber; por el contrario, esta misma se conceptualiza como un proceso dinámico cuyo propósito principal es el desenvolvimiento científico y técnico de diversas ramas disciplinarias, que funcionan de forma integrada, para atender una necesidad o situación de manera acertada y efectiva. (p. 5)

\section{Presentación}

En el contexto del TEI los desafíos éticos, entendidos en su dimensión temporal como aquellos retos o metas que se pretende alcanzar en el tiempo, tendrían directa relación con aquellas tensiones y/o dificultades con las cuales nos encontramos en el quehacer profesional, y que se vincularían a la puesta en común del marco ético que deberíamos consensuar para llegar a la toma de decisiones. Dichos aspectos nos ayudarían a encaminar nuestras acciones.

Entre los desafíos o retos del quehacer profesional cabe mencionar, por ejemplo, decir la verdad, guardar la confidencialidad de la infor- 
mación recibida, respetar la autonomía, promover el bienestar, la integridad y vida de las personas, preservar los intereses de los usuarios y terceras personas, respetar los intereses institucionales, denunciar situaciones que involucran o afectan a compañeros de trabajo, entre otros.

Se debe tener en cuenta que el quehacer disciplinar y profesional va adquiriendo gradualmente una serie de complejidades en contextos cada vez más dinámicos y cambiantes. Un ejemplo de ello es la devaluación del tiempo, la que estaría impactando la significación y el sentido de las prácticas laborales, ello estaría en directa relación con la pérdida y ausencia de la dimensión contemplativa, que debiese estar presente para reflexionar sobre nuestro quehacer en el espacio laboral. Esta consideración es abordada en sus estudios por el filósofo surcoreano Byung-Chul Han en el siguiente postulado:

La atomización, el aislamiento y la experiencia de discontinuidades también son responsables de diversas formas de violencia. En la actualidad, cada vez se desmoronan más estructuras sociales que antes proporcionaban continuidad y duración. La atomización y el aislamiento se extienden a toda la sociedad. Las prácticas sociales, tales como la promesa, la fidelidad o el compromiso, todas ellas prácticas temporales que crean un lazo con el futuro y limitan un horizonte, que crean una duración, pierden importancia. (Han, 2015, p. 32)

Frente a la imposibilidad de la demora, el "animal laborans" 3 valora y potencia al máximo el rendimiento propio, a partir de la presunción del absoluto poder del Yo. De esta manera, se va generando la expulsión del Otro por la necesidad de reproducción del Sí mismo. Tal necesidad solo encontraría asidero en aquellos en los cuales me reflejo, en aquellos semejantes, en aquellos que no representan ninguna amenaza a la mismidad. De esta manera, la Otredad generaría una reacción inmunitaria-expulsiva. Es así como, ante aquello que se nos presenta distinto, construiríamos límites y muros que impedirían los procesos de cambio e intercambio (Han, 2015).

3 Término expresado por Han (2015) para representar la posición de las personas en la sociedad del rendimiento. 
Si bien el autor, por medio de sus aportaciones, ilustra acerca de las características del problema, resulta importante señalar que, en alternancia con el planteamiento que nos ofrece el paradigma inmunológico ${ }^{4}$, existiría otro pensamiento propuesto por Levinas, el que, como contraparte, plantea un horizonte de posibilidades por medio del significado que otorga al encuentro con otras personas, "El Otro no es inicialmente hecho, no es obstáculo, no me amenaza de muerte" (Levinas, 2002, p. 106).

Teniendo en cuenta que el TEI constituiría en sí mismo un desafío, al tener que trabajar con una diversidad de personas, debiésemos tomar cada vez más conciencia acerca de que tal encuentro se nos presentaría no como amenaza, sino como una condición de posibilidad para la generación de procesos de creación colectiva. Cabe agregar que en este tipo de trabajo se hacen presentes distintas miradas e interpretaciones de la realidad, por lo que surgiría la siguiente interrogante: ¿cómo elaborar categorías interpretativas que pudiesen superar los saberes y lenguajes disciplinarios a partir de un acto de entendimiento recíproco, logrando con ello confluir en un mismo horizonte de sentido? Como respuesta y en cuanto condición a priori para posibilitar dicho propósito, resulta fundamental fomentar procesos de intercambio de miradas mediante la facilitación del diálogo. "Todo acto de entendimiento puede entenderse como parte de un proceso cooperativo de interpretación, que tiene como finalidad la obtención de definiciones de la situación que puedan ser intersubjetivamente reconocidas" (Habermas, 1987, p. 103).

El trabajo en equipo interdisciplinario nos invita, por algunos momentos, a entregar el saber disciplinario al servicio de un propósito que es común, así como también, en cuanto desafío ético, a respetar los otros saberes en la posición o lugar en que se encuentran los demás integrantes del equipo, reconociendo su condición de alteridad ${ }^{5}$. Este propósito se asocia específicamente con las complejidades que representa para los equipos la atención de personas y familias diversas, la

4 El paradigma inmunológico se relaciona con la idea de resistencia inmunitaria, la cual se dirige siempre contra lo otro, o aquello que interpretamos como extraño en sentido empático.

5 "Alteridad", término que según Levinas (2002) alude a la heterogeneidad radical de lo Otro. 
búsqueda de solución a problemas complejos y la toma de decisiones sobre éstos. De esta manera, el TEI se presenta en cuanto medio para abordar, procesar y arribar a resultados exitosos en la actuación profesional, entendiendo que:

La interdisciplinariedad es un intento, una propuesta de enfrentar y abordar problemas complejos mediante el diálogo y la colaboración de distintas disciplinas, con el fin de lograr una comprensión más profunda de esos problemas mediante la síntesis de los diferentes aportes disciplinares. (Solana, 2016, p. 6)

\section{Consideraciones en torno a los desafíos éticos del trabajo en equipo interdisciplinario}

A continuación se presentan, a modo de síntesis, algunos aspectos relevantes a tener en cuenta cuando nos enfrentamos con la serie de desafíos éticos en el trabajo en equipo. Dichos aspectos son seis, entre los cuales se exponen variables contextuales e intraequipo. En relación con estas últimas, se analizan algunas diferencias-disonancias que aparecen durante el encuentro entre los integrantes del equipo interdisciplinario, y que pueden tensionar o aperturar en cuanto posibilidades la resolución de desafíos o dilemas éticos, como son: la complejidad de los temas a abordar, las distintas miradas y saberes disciplinares, los conflictos de interés y las divergencias siempre presentes en proceso de deliberación colectiva para la toma de decisiones.

\section{La creciente complejidad de los temas que abordan los equipos de trabajo}

Este aspecto dice relación con que las situaciones que usualmente se presentan en el ámbito cotidiano laboral, y que afectan a las personas y familias atendidas, revisten cada vez mayor complejidad en términos del nivel de vulnerabilidad y/o daño que conllevan, como también, respecto de la serie de dimensiones que comprenden y que deben ser tenidas a la vista al momento de la evaluación y actuación profesional. Estas situaciones, a las cuales nos enfrentamos permanentemente, pueden generar incertidumbre, ya que nos vemos impelidos a comenzar a hacernos cargo de nuestra incapacidad para vislumbrar con certeza posibles horizontes de solución a las dificultades que nos plantea la praxis. Ante lo indecible, pareciera ser que no existen res- 
puestas simples y seguras; además, el repertorio disciplinar resulta insuficiente, pese a que hemos experimentado la tendencia de reducir la experiencia a ciertos sectores limitados del saber disciplinar, acostumbrados además a fragmentar la realidad, poniendo en acción, la más de las veces, un tipo de pensamiento reduccionista sobre la misma "como si la verdad estuviera encerrada en una caja fuerte de la que bastara poseer la llave" (Morín, 1995, p. 17).

La perspectiva del pensamiento complejo, de Morin, nos señala que mantendríamos una tendencia inconsciente a descartar de nuestro espíritu aquello que contradice nuestras ideas, rechazando argumentaciones contrarias. En forma alterna, atenderíamos selectivamente aquello que favorece o es consecuente con nuestros planteamientos (Morin, 1995). Continuando con este análisis, resultaría entonces imprescindible que los equipos de trabajo puedan internalizar la necesidad de reconocimiento de la cualidad de valor del pensamiento divergente y de la complejidad de lo real. Asimismo, advertir que la complejidad representaría el comienzo de un desafío, cuya significación teleológica promovería un horizonte de sentido para la praxis.

Si llegamos a percatarnos, en este momento, de la suma relevancia de las aportaciones del autor, podemos comenzar a advertir que, por medio de la aceptación y reconocimiento del Otro en toda su alteridad, y a través de nuestra disposición a mirar la realidad desde un prisma de totalidad, nos encontraremos en mejor condición para enfrentar la incertidumbre siempre presente en los límites de nuestro entendimiento: "en última instancia, todo es solidario. Si tenemos sentido de la complejidad, tenemos sentido de la solidaridad. Más aún, tenemos sentido del carácter multidimensional de toda realidad" (p. 63).

\section{El reconocimiento del marco ético-político e institucional}

Los desafíos éticos que se presentan en la práctica se enmarcarían en un contexto ético-político asociado con la institucionalidad y aquellas orientaciones de valor que forman parte del horizonte de sentido que promueven las instituciones, generalmente contenidas en la visión, misión y objetivos que estas poseen, como también, en términos operacionales, en la serie de lineamientos técnicos y procedimientos que guían la actuación profesional de los equipos de 
trabajo. Por ende, resulta necesario tener presente este importante aspecto al momento de abordar los desafíos éticos que se presentan en la actuación profesional. Ello permite analizar la influencia que pudiera estar teniendo la dimensión ético-política en el trabajo de los equipos y que eventualmente pudiera entrar en conflicto con el abordaje de problemáticas complejas. y que frecuentemente se asocian a dilemas éticos. Al respecto, se entenderá por este concepto "una elección entre dos alternativas igualmente inadecuadas para el bienestar humano" (Banks, 1997, p. 20).

Los dilemas éticos con los cuales se encuentran usualmente los equipos en su actuación profesional se asocian con deberes y principios que entran en conflicto; por ejemplo, actuar con honestidad, conflicto de intereses, secreto profesional, respeto a la autonomía de las personas, consentimiento informado, relaciones con compañeros de trabajo, entre otros. Se advierte que él o los profesionales que vivencian estos dilemas en sus prácticas cotidianas presentarían en ocasiones una especie de atrapamiento e incertidumbre respecto de su abordaje y vías de dilucidación y resolución, siendo este momento en el cual se requiere de máxima apertura y reflexividad por parte de los integrantes del equipo interdisciplinario. Ello se facilitaría desarrollando formas de pensamiento complejo, por medio de la revisión epistemológica permanente de nuestros saberes al servicio del trabajo en equipo, tomando en cuenta de que "estamos condenados al pensamiento incierto, a un pensamiento acribillado de agujeros, a un pensamiento que no tiene ningún fundamento absoluto de certidumbre. Pero somos capaces de pensar en esas condiciones dramáticas" (Morín, p. 101). Agregando a este planteamiento del autor que, si esta forma de pensamiento se da en equipos interdisciplinarios, el análisis colectivo de situaciones complejas en contextos de incertidumbre operaría a modo de contención, teniendo además un efecto sinérgico muy positivo para la búsqueda de consensos y la toma de decisiones. Por ello, resulta fundamental que las instituciones instauren y mantengan espacios de contención, acompañamiento y asesoría técnica permanente para el abordaje de situaciones complejas en equipo interdisciplinario, lo cual debiese ampliar el discernimiento y la visión de totalidad en su abordaje, promover procesos de deliberación colaborativa, tomar decisiones consensuadas y definir acciones coordinadas y complementarias. 


\section{La forma en que se logra compatibilizar las distintas miradas y saberes en un equipo de trabajo}

Uno de los retos más importantes del TEI es cómo lograr compatibilizar distintas miradas y saberes en pro de un propósito colectivo. Al respecto se requiere lograr un salto cualitativo, según lo señalado en este mismo texto, cual es la construcción de una interpretación consensuada que otorgue un horizonte de sentido al TEI, y actúe como motor de una serie de acciones orientadas hacia un fin que es común. Pero también, y en razón de lo señalado al inicio del párrafo, no es menos cierto advertir lo que nos señala García (2021):

En muchas ocasiones se da a entender que la interdisciplina se corresponde con una perspectiva unificadora u holista del conocimiento, dejando de lado que no es en abstracto que ello se da, sino en torno a una problemática que demanda una aproximación en la que varias áreas disciplinares estén involucradas y se articulen, que entren en interrelación para dar cuenta de ella. (García, 2021, p. 16)

Para el logro de la condición que plantea este tercer punto se requiere de la apertura en cuanto epistemología abierta de cada integrante del equipo, para recibir y aceptar saberes y opiniones distintas al saber y ámbito disciplinar de cada cual en torno a un mismo tema. En el mismo punto, en ocasiones el celo profesional puede actuar como freno a dicho propósito, y puede ocasionar la imposición de un saber sobre otro. Quizás este factor, que se presentaría como un obstaculizador del trabajo en equipo, se comprenda mejor teniendo a la vista un importante antecedente histórico mencionado por Foucault en sus investigaciones:

El siglo XVIII fue el siglo del disciplinamiento de los saberes, es decir, la organización interna de cada uno de ellos como una disciplina que tiene, en su campo de pertenencia, a la vez criterios de selección que permiten desechar el falso saber, el no saber, formas de normalización y de homogeneización de los contenidos, formas de jerarquización y, por último, una organización interna de centralización de esos saberes en torno de una especie de axiomatización de hecho. (Foucault, 2000, p. 170)

Si analizamos el planteamiento del autor y nos aproximamos a generar una relación con el paradigma inmunológico propuesto por Han 
(2015), nos encontraríamos con que el ámbito del saber de cada disciplina (entendida en toda su complejidad epistémica) presentaría cierta resistencia por su exceso de positividad a la negatividad de lo distinto. He aquí que se correría frecuentemente el riesgo, en el trabajo en equipo, de ejercer, por medio de una posición asimétrica o de altura, el predominio del "propio saber" frente a "otros saberes". Este aspecto se constituiría en un factor obstaculizador para la promoción del TEI, ya que lo que se requiere para favorecer este tipo de trabajo es la internalización gradual de cada uno de los integrantes del equipo, respecto de la importancia de la superación de la colonización del pensamiento, en pro del fomento de la donación del propio saber a la confluencia de una forma de pensamiento y fin común, concordante además con la dimensión teleológica del trabajo en equipo. En síntesis, este aspecto se constituiría en un desafío ético muy importante, previa aceptación de las naturales diferencias entre diversos integrantes, poseedores de diversos saberes, lo cual plantea una condición muy propicia para estimular el diálogo interdisciplinar, previniendo con ello tener que recurrir a la violencia de "anular" o "someter" al Otro a "mi propia visión de la realidad”. En este mismo tópico Levinas nos ilustra:

Pero el Otro, absolutamente otro -Otro- no limita la libertad del Mismo. Al llamar a la responsabilidad, la instaura y justifica. La relación con el otro en tanto que Rostro sana de la alergia. Es deseo, enseñanza recibida y oposición pacífica del discurso. (Levinas, 2002, p. 2010).

En el planteamiento anterior el autor alude a la idea de infinito, la que se produce en la socialidad por medio del recibimiento del Rostro del Otro, pues "la resistencia del Otro no me hace violencia, no obra negativamente; tiene una estructura positiva: ética" (Levinas, 2002, p. 2010).

Tomando en cuenta los aportes de Levinas, podemos apreciar que los Otros, en su alteridad, no constituirían una amenaza a las certezas que nos conferiría nuestro ámbito del saber disciplinario, muy por el contrario: en la relación de encuentro y trabajo con Otros podemos complementar todos aquellos repertorios desde cada uno de los ámbitos del propio saber disciplinar, pudiendo confrontar y corregir nuestras incertidumbres, y generar así meta-puntos de vista en pro de un objetivo común. 
Por otra parte, se debe tener también en cuenta la presencia y la forma en que se desempeñan los liderazgos en el equipo por parte de cada uno de sus integrantes, en aquella posición y/o rol que le corresponda ejercer, ya que dicho rol tendría una tarea ineludible para la orientación de sentido que tenga el trabajo en equipo, pudiendo actuar, desde su calidad, en cuanto facilitador u obstaculizador para la concreción de dicho propósito. Se propone para ello una actitud facilitadora del rol de liderazgo al interior del equipo, el que debiese constituirse en un liderazgo situacional y colaborativo que, como señala Cabrera en sus estudios sobre organizaciones duales, "no tiene su origen, por tanto, en el puesto que ocupamos, sino en nuestra actuación proactiva como líderes, basada en nuestra pasión y constancia, nuestra autoconfianza y nuestra capacidad de decidir" (Cabrera, 2017).

\section{La puesta en práctica permanente del diálogo interdisciplinario}

Para efectuar un análisis acerca de este tema, resulta relevante mencionar que toda posibilidad de diálogo entre personas e integrantes de un equipo de trabajo posee generalmente, como valla, la dimensión temporal en la cual se inscribe la praxis cotidiana. Tal obstáculo generaría la sensación de "un estar" frecuentemente a des-tiempo, sin posibilidad de asimilar el tiempo presente, "las prisas, el ajetreo, la inquietud, los nervios y una angustia difusa caracterizan la vida actual" (Han, p. 48). A esto se agregan los múltiples requerimientos y metas de cumplimiento que presionan y tensionan permanentemente las prácticas de los equipos en contexto institucional, pero esto también encuentra explicación en el alto nivel de autoexigencia que posee un componente de responsabilidad individual, como muy bien ilustra Han cuando hace mención a aquella pseudo-libertad de la autorrealización que creemos encontrar a partir de la consigna "yo puedo", muy propia de la sociedad del rendimiento. El drama de la aceleración es un fenómeno de los últimos siglos. Se puede decir que se trata de un drama, puesto que la aceleración va acompañada de una narración:

La desnarrativización (entnarrativisierung) desdramatiza la trayectoria acelerada y la convierte en un sumbido (schwirren) sin rumbo. Al fin y al cabo, el drama de la aceleración tampoco llegará a su fin 
cuando la velocidad de transmisión de los acontecimientos y las informaciones alcance la velocidad de la luz. (Han, p. 49)

Siendo esto así, el diálogo entendido como posibilidad de encuentro entre personas se constituiría en oportunidad para dotar de reflexividad y significación al quehacer, recuperando la estacionalidad del tiempo y con ello el pensamiento complejo y crítico:

El diálogo hace posible, en suma, la presencia de una corriente de significado en el seno del grupo, a partir de la cual puede emerger una nueva comprensión, algo creativo que no se hallaba, en modo alguno, en el momento de partida. Y ese momento es el "aglutinante", el "cemento" que sostiene los vínculos entre las personas y las sociedades. (Bohm, 1997, p. 30)

La tesis de Bohm permite comprender que, para posibilitar un auténtico diálogo, debemos reconocer la posibilidad de ser partícipes de la generación de nuevas miradas respecto de nuestro quehacer y a estar dispuestos a cuestionar nuestras opiniones y creencias fundamentales sobre distintos temas. Esta idea nos enfrenta también a incorporar una mayor apertura y flexibilidad acerca de diversos escenarios o ámbitos de actuación, especialmente de aquellos que desafían nuestros conocimientos y certezas, sobre los que usualmente debemos tomar algunas decisiones. No obstante, en ocasiones este ejercicio presenta ciertas dificultades en su concreción, ya que generalmente las creencias se asocian con nuestros principios y valores en ámbitos diversos (políticos, religiosos, económicos, culturales). Siendo esto así, las interpretaciones y opiniones que poseemos sobre ciertos fenómenos (las que incluso han sido asumidas como verdades) se asocian a creencias y simbolismos que defendemos cuando alguien nos confronta con ellos. Esta condición representaría una visión fragmentada de la realidad, forma de pensamiento que usualmente ponemos en práctica para aproximarnos al conocimiento. Para lograr gradualmente la superación de esta forma de pensamiento, Bohm propone pensar en forma individual y colectiva, pero este segundo aspecto es el que resulta necesario profundizar para los efectos del presente análisis, ya que, tomando en cuenta la pluriversalidad presente en el diálogo, podemos tomar conciencia gradual en torno a que, si bien podemos compartir opiniones y creencias muy diversas, el fin que queremos lograr es el mismo; por ende, corremos permanentemente el riesgo de perder el 
sentido acerca del propósito que "nosotros" queremos lograr, quedando atrapados en una discusión sobre puntos de vista diferentes (1997).

El término "discusión" subraya la idea de análisis, de personas que sostienen puntos de vista diferentes y que, en consecuencia, conciben y desmenuzan también las cosas de modo distinto, lo cual, obviamente, tiene su importancia, pero resulta limitado y no nos permite trascender la divergencia de puntos de vista.(Bohm, p. 30)

En ocasiones parecería que el objetivo sería "ganar" en términos unipersonales; a diferencia de la discusión, nos aproximamos en el diálogo a la expresión "todos ganan".

El diálogo interdisciplinario se posibilita a través de la generación, y de la instauración, de instancias de encuentro de equipo por medio del intercambio permanente que facilita la comunicación, pero una comunicación basada en primer lugar en el recibimiento y reconocimiento del Otro (Levinas, 2002), ya que en el intercambio comunicativo emerge la ética, porque cuando reconocemos nuestras diferencias con otras personas estamos reconociendo su alteridad, y así podemos entablar un diálogo auténtico para llegar a acuerdos en los temas atingentes al quehacer profesional.

Intentando agregar otros elementos a los postulados del autor, se puede mencionar que el diálogo interdisciplinar promueve la adquisición de un saber que difícilmente podríamos incorporar desde nuestra propia posición autocentrada o campo disciplinar, permitiéndonos ampliar la mirada en la comprensión de los hechos, así como también ser creativos en la deliberación respecto de alternativas de solución a los desafíos éticos que usualmente se nos presentan en la cotidianeidad laboral.

\section{El abordaje y resolución colaborativa de los conflictos de interés}

Permanentemente, trabajar con otros plantea la necesidad de un trabajo colaborativo, el que no necesariamente se posiciona en dichos términos desde el primer momento. También, debemos considerar que dicho desafío se presenta natural a las también naturales diferencias-disonancias en el encuentro con otros distintos, como se señaló en los puntos anteriores, y que están referidas a las diferentes mira- 
das y saberes que posee cada integrante del equipo, en los que además aparecen una serie de conflictos de intereses, como aquellos que afectan a las personas con las cuales trabajamos, a terceras partes, a la institución u organización en la cual laboramos, entre otros.

La búsqueda de soluciones a los diferentes temas que se nos presentan en la praxis requiere de algunas condiciones, como la actitud de apertura y colaboración que debe tener cada una de las partes interesadas en los temas que representan desafíos éticos. Esta actitud se asociaría, en primera instancia, con la generación de la capacidad de escucha activa y buen trato entre cada una de las partes que participan de la situación que representa un conflicto, evitando recurrir a la violencia para anular o desconfirmar aquel planteamiento distinto al nuestro, o someter al otro a mi propia visión de mundo, dado que "es en la escucha y el diálogo donde el mundo se hace común” (Levinas, 2002). Ante esto resulta fundamental que, en forma permanente, revisemos las relaciones que establecemos con otros; por ejemplo, preguntarnos desde dónde nos situamos, cuál es nuestra capacidad de atención y escucha activa hacia los demás, y nuestra intencionalidad afectiva y capacidad de diálogo, puesto que:

El diálogo interdisciplinar y la cooperación entre diferentes especialidades profesionales no llega a establecerse si cada uno hace su propio oficio, se mantiene en su campo y no se sale de sus métodos. Ateniéndose cada cual a su propia especialidad y a su propio método lo más que puede alcanzarse es un mero intercambio de informaciones, una yuxtaposición de los distintos saberes parciales sin posible mediación ni cuestionamiento mutuo. Sólo los visionarios de una armonía prestablecida pueden dar por supuesto que las diferentes actuaciones y los diferentes conocimientos se ajustarían unos con otros como las piezas de un rompecabezas, para ofrecer entre todos una prestación profesional integrada. (Hortal, 2002, p. 105)

Debiéramos entonces tener en cuenta que el trabajo en equipo se encontrará generalmente influido por tensiones y oportunidades. Las tensiones tendrán relación con los conflictos que también podemos significar como oportunidades, ya que, por medio del cuestionamiento de nuestros saberes individuales y colectivos, se podrá dar paso a la articulación de un horizonte común. Para propiciar formas de convergencia y 
de mediación de conflictos de intereses, resulta importante que quien coordina y lidera el equipo debe saber escuchar, construir el consenso y la cooperación (Hortal, 2002). No obstante, y agregando otro elemento al planteamiento del autor, esta no debería constituirse solo en una tarea y/o responsabilidad de quien lidera, sino de todos los integrantes del equipo, en cuanto ejercicio de corresponsabilidad, entendida como responsabilidad compartida. Adela Cortina (2017) nos ilustra asertivamente sobre la importancia de este tema: “(...). Ni siquiera la responsabilidad organizacional es suficiente en un mundo globalizado e interdependiente, sino que es necesaria una ética de la corresponsabilidad, del trabajo conjunto entre los distintos agentes" (p. 10).

\section{La toma de decisiones basadas en la divergencia y el consenso}

La toma de decisiones procede en el momento en que ha transcurrido el proceso de deliberación de la situación que representa para el TEI un desafío o dilema ético. Previo a ello, como ilustra el autor Hortal, cada profesional debe aportar los conocimientos y habilidades que el caso requiere, conforme a los criterios y en el lenguaje de su profesión: Pero el autor va más allá inclusive, cuando señala que:

Se requiere ir generando formas de "bilingüismo asimétrico", es decir, saber hablar el propio lenguaje profesional, saber hacerse entender por quiénes no tienen esa misma profesión, y saber comprender los lenguajes ajenos, aunque nunca uno pueda llegar a dominarlos con competencia propia. (p. 106)

Dicho proceso concluye con una o más decisiones, dependiendo del caso o situación que el equipo esté abordando en un momento determinado. Antes, debió enfrentar la necesidad de tomar en cuenta distintas posiciones e intercambiar referentes epistemológicos, axiológicos y normativos, por nombrar algunos, que nos pueden ayudar en la deliberación y toma de posición consensuada sobre temas asociados a las prácticas de evaluación e intervención, de manera de arribar en mejores condiciones a la toma de decisiones y cursos de acción a seguir. No obstante, cabe precisar que la finalidad de todo este proceso, cual es llegar a la toma de decisión, pasará en un momento o quedará suspendido por la divergencia de posiciones y opiniones en torno a formas de actuación profesional, resolución de casos y cursos 
de acción a seguir ante una situación determinada. Este desafío recibe la influencia de las naturales diferencias que se pueden presentar en el trabajo interdisciplinario y que pueden tener asociación con los siguientes aspectos, algunos de los cuales ya han sido abordados en alguna medida en el artículo:

- Con la creencia de que nuestra cosmovisión de la realidad es la correcta, lo cual se explica, según se mencionó, por medio del convencimiento de que nuestro saber disciplinar debiera predominar ante otros saberes (supremacía epistémica), ya que tendría un mayor nivel de teorización y/o comprensión cognoscitiva, e incluso metodológica, respecto del tema o fenómeno investigado y/o abordado.

- Con la apropiación inconsciente o consciente de la situación que tenemos en frente en el trabajo con otros. Este aspecto tendría relación con aquella forma de pensamiento asociada a que los casos o situaciones que abordamos serían de nuestra propiedad.

- Con una forma de pensamiento que transcurre entre la visión fragmentada o totalizante de la realidad, lo cual en ocasiones nos haría perder de vista aquello que es urgente y prioritario.

- Con el atrapamiento o triangulación con el caso o situación que abordamos, aspecto que pudiera estar incidiendo en la forma en que nos vinculamos con el Otro y en la proyección que hacemos del mismo en el tiempo.

Por otra parte, la natural disonancia que nos produce el pensamiento complejo y divergente debiese ser reconocida como una "fuerza” para el TEI. No obstante, resulta necesario tener presente una advertencia de Bohm (1997), en orden a que deberíamos estar preparados para aceptar que nuestras teorías no serían necesariamente descripciones de la realidad tal como ésta es, sino formas de observación siempre cambiantes y que estarían dando cuenta de una visión fragmentada de la realidad. Complementando esta idea, el autor menciona: "la totalidad es solamente un ideal, por el que tal vez deberíamos esforzarnos" (p.12).

Solo si tomamos conciencia, gradual y permanente, del dinamismo y complejidad de la realidad en la cual participamos cotidianamente 
en el trabajo individual y colectivo al cual nos orientamos y del cual formamos parte, podremos arribar a mejores decisiones en aquellos procesos de deliberación colectiva, en el trabajo en equipo, por medio de una comprensión de la realidad desde una visión de totalidad.

\section{Elementos a tener en cuenta en la elaboración de un marco ético para el abordaje y resolución de los desafíos o dilemas de la praxis}

Uno de los principales desafíos que enfrenta el TEI es cómo desarrollar, durante el proceso de despeje y deliberación de situaciones o dilemas en el quehacer profesional, un marco ético que permita abrirse paso a través de los conflictos y divergencias que aparecen en dicho proceso - los que, como ya se ha señalado, se asocian frecuentemente con la atención y resolución de temas vinculados a los casos atendidos, conflictos de intereses, toma de decisiones y cursos de acción a seguir-. Para lo anterior resulta necesario clarificar qué entendemos por deliberación. Según Bellver, "deliberar es un ejercicio de ponderación de los pros y contras de los diversos cursos de acción que se plantean ante una determinada situación" (Bellver, 2004, p. 441). Parafraseando al autor, se trataría de un ejercicio que puede ser de índole individual o colectivo, que consistiría en la valoración de diversas alternativas o posibilidades para llegar a aquella que se considera la más idónea para alcanzar un fin, incluyendo bienes morales en juego, conflicto entre derechos, entre otros (Bellver, 2004).

El despeje de desafíos o dilemas se realizaría la mayoría de las veces en forma espontánea, a partir de la improvisación mediatizada por el apremio del tiempo ${ }^{6}$. No obstante, como condición de posibilidad para la mejora de nuestras prácticas, debería surgir la pregunta por la existencia de una ética universal, ya que, como señala Bellver, si bien en el último tiempo se habría extendido la idea de que los principios éticos son relativos, aún hoy existe consenso acerca de principios éticos con vigencia universal (p. 438).

6 Para los efectos del presente estudio, entiéndase como "apremio del tiempo" el cumplimiento de urgentes, múltiples y crecientes tareas en el contexto del tiempo que transcurre veloz. 
Por otra parte, entre las razones aludidas para el reconocimiento de principios universales aparece la tendencia natural a hacer el bien. Es así como, en el trabajo, las personas intentarían realizar su labor con una orientación o finalidad; para ello, la persona trataría de hacer las cosas lo mejor que sabe. Esto se presentaría en aquellas profesiones que suponen un servicio a los demás. Paralelamente, surgen algunas interrogantes cuando nos vemos ante algún dilema asociado a la praxis y en el cual aparecen una serie de conflictos de interés, por ejemplo, ¿qué es correcto hacer? ¿qué decisión debemos tomar como equipo? $\mathrm{Al}$ respecto, quizás sería atingente detenernos en aquello que Aranguren (1998) denomina "moral pensada", pudiendo así asociar este concepto con la importancia de la reflexión ética para la conformación de un pensamiento colectivo, intersubjetivo y dialógico, más allá de la observancia y práctica de una moral vivida, la que además sería predominantemente subjetiva y autorreferencial.

Para esbozar un marco ético para la resolución de desafíos o dilemas resulta menester relevar la importancia de ir construyendo comunidades de diálogo, que serían las encargadas de discernir acerca de aquellos fenómenos que requieren usualmente nuestro abordaje y resolución. En este instante cobra relevancia la ética del discurso, que ofrece un camino de entendimiento mutuo entre personas en torno a la universalización de intereses, en cuanto resultado de un discurso colectivo organizado intersubjetivamente. Según refiere Habermas, "los sujetos capaces de hablar y de actuar solamente se constituirán como individuos en tanto que, en calidad de miembros de su respectiva comunidad lingüística particular, crezcan y se integren en un mundo de la vida compartido intersubjetivamente" (Habermas, 2000, p. 18).

Desde la conformación gradual de una comunidad de diálogo en los diversos espacios colectivos, para efectos del trabajo en equipo se incentivaría la superación de aquellas perspectivas egocéntricas, que dificultan aquella disposición solidaria de cada uno de los integrantes del equipo a reconocer la perspectiva de validez del discurso de un otro que es distinto a mí, pero cuya diferencia y divergencia discursiva puede constituirse en un aporte, tal como sucede al acceder a un entendimiento mutuo sobre la pluriversalidad de miradas e intereses sobre un tema específico. De esta forma cabe destacar que "el diálogo interdisciplinar y la cooperación entre diferentes especialidades pro- 
fesionales no llega a establecerse si cada uno hace su propio oficio, se mantiene en su campo y no se sale de sus métodos" (Hortal, p. 105).

Una vez teniendo en cuenta las reflexiones anteriores, nos encontraríamos en condiciones para comenzar a esbozar un marco ético que incorpore una especie de ruta para la toma de decisiones y acciones posteriores a realizar, para alcanzar el fin que nos hemos propuesto como equipo de trabajo:

- El primer aspecto a abordar sería clarificar y definir expresamente cuál es el tema que nos convoca a iniciar un proceso de dilucidación y deliberación, entre aquellas posiciones y opiniones diversas que aparecen durante el diálogo en el trabajo en equipo. Ello ya que se puede presentar una eventual confusión, producto de una comunicación defectuosa, a partir de la escasa claridad en cuanto al tema que estamos abordando, o bien a su abordaje desde planos e interpretaciones distintos.

- Posteriormente, es preciso revisar cuáles son aquellos máximos y mínimos éticos que vamos a incorporar en el análisis de la situación o hecho que estamos abordando, como por ejemplo valores, principios, deberes y normas que forman parte de nuestro repertorio ético-profesional. Se trataría de una oportunidad, en esta primera práctica del trabajo interdisciplinario, de realizar un intercambio generoso de nuestros esquemas o configuraciones axiológicas y normativas que influencian el entendimiento y comprensión de los temas que abordamos en el contexto laboral. Ya que, como señala Bellver (2004), frecuentemente se presentarían más diferencias en la interpretación que en los principios:

En los últimos tiempos se viene haciendo hincapié en las diferentes respuestas en que las culturas y comunidades ofrecen a los mismos problemas, Siendo obvio que existen esas diferencias no se puede perder de vista que, por lo general, es mucho más lo que de común existe en ellas. Esas diferencias provienen, en la mayor parte de los casos, de la distinta interpretación que se hace de los hechos y no de los principios morales de los que se parte. p. 439)

En este mismo punto cabe hacer presente que el examen del marco deontológico general de los principios profesionales y de las normas jurídicas implicadas en la situación abordada, forma parte del reper- 
torio ético de cada disciplina y/o profesión. Específicamente, resulta importante rememorar aquellos aspectos normativos y reglamentarios contenidos en el Código de Ética de cada profesión y/o disciplina, los que pueden confluir y aportar en forma significativa a la deliberación de un dilema o desafío ético al cual nos podemos ver enfrentados, así como iluminar actuaciones profesionales efectivas y responsables. Al respecto, y parafraseando a Hortal, los códigos profesionales suelen hacer referencia a aquello que la profesión exige de los profesionales y lo que se espera del buen ejercicio profesional. No obstante, en este punto resulta necesario prevenir un eventual peligro al cual nos podemos ver enfrentados. Según Bermejo, cuando se hace referencia a la centralidad del código, "un peligro muy común proviene de la sacralización casi dogmática del código profesional” (2002, p. 8). Efectivamente de esta idea se puede inferir que el Código de Ética Profesional no lo es todo, ya que cada área disciplinar-profesional cuenta con otros referentes teóricos, metodológicos y éticos que posibilitan una actuación profesional acorde a un campo que le es propio.

Continuando en la dimensión deontológica, se trataría de hacer un buen uso de los referentes axiológicos y normativos contenidos en los códigos profesionales, textos en los que se encuentran disponibles, en cuanto marco ético, principios y normas éticas de características muy similares y que orientan la actuación profesional. Entre ellos se cuenta, por ejemplo, el respeto por la dignidad y derechos de las personas, a la autonomía, a la confidencialidad, al secreto profesional, al consentimiento informado, entre otros.

Finalmente, la serie de elementos que forman parte de nuestro repertorio profesional aporta y confluye en la elaboración de una postura de equipo coherente con la toma de decisiones sobre aquellos desafíos éticos que plantea la praxis, siempre recreándose en cuanto proceso orientado por un sentido y finalidad, que es también resultado de un ejercicio intersubjetivo y dialógico que respeta los aportes de cada uno de los integrantes desde su particular mirada y contribución al TEI.

\section{Conclusiones}

En el artículo se intentó realizar una serie de aportaciones referidas a los desafíos éticos de la actuación profesional, en una sociedad e institucionalidad fragmentada y cambiante, condición que dificulta 
la comprensión totalizante de los fenómenos a los cuales se enfrenta el TEI.

Se hace presente también, a modo de reflexión final, que el marco contextual e institucional en el cual se sitúa y desarrolla el trabajo de los equipos estaría teniendo un impacto en las prácticas, por medio de una serie de factores que actuarían como obstaculizadores del quehacer, como aquellos que ilustra Han cuando hace referencia al "tiempo sin aroma" y a "la sociedad del rendimiento". A partir de este pensamiento se infiere la falta de tiempo que padecen hoy los equipos de trabajo para pensar y habitar la praxis, con el consiguiente efecto en la ausencia de un horizonte de sentido que permita otorgar significado y valor a la misma. En el mismo tópico, el autor concluye: "quien se queda sin aliento no tiene espíritu, la democratización del trabajo debe ir seguida de una democratización del otium, para que aquella no se convierta en la esclavitud de todos" (Han, p. 157).

Por otra parte, cabe detenerse en las posibilidades que nuevas corrientes epistemológico-teóricas ofrecen para orientar la reflexión de la praxis, las que se van abriendo paso gradualmente al tradicional pensamiento de las ciencias positivas y al estructural/funcionalismo. Un ejemplo de ello es el posicionamiento y reconocimiento que gradualmente va logrando la valoración de la intencionalidad afectiva, siempre presente en nuestra praxis por medio de actos afectivos y volitivos. Ello permitiría pensar respecto de algo que va más allá que lo que nos ofrece la razón instrumental y nuestra conciencia lúcida, aquello que es esencial y que estaría presente como potencial en el momento del encuentro y en el reconocimiento incondicional de la alteridad del Otro. Según Pérez de la Fuente, "las reflexiones sobre alteridad suelen ser reflexiones sobre el límite de lo propio, lo extraño, lo exótico y, en fin, en cierta medida, lo desconocido" (Pérez de la Fuente, 2019, p. 10).

Para abordar los desafíos éticos del TEI se debe entender, en primera instancia, que cada integrante forma parte de una red, en la que cada uno tiene un valor único, reconociendo en él su dimensión de alteridad, representando un rol relevante, "imprescindible" para el trabajo en equipo interdisciplinario. Dicha premisa debiese constituirse en un imperativo y responsabilidad ética en el marco institucional, y en una condición sine qua non para posibilitar y dar paso a los proce- 
sos de deliberación colectiva de desafíos y/o dilemas éticos propios del quehacer y actuación profesional, a nivel de contextos institucionales y sociales cada vez más complejos e inciertos.

Levinas nos plantea, a partir de sus estudios, la necesidad de la superación del Yo y la apertura que debiese darse al Otro:

El Yo en la negatividad que se manifiesta por la duda, rompe la participación, pero no encuentra en el cogito solitario un alto. No soy Yo, es el Otro quien puede decir sí. De él viene la afirmación. Él está en el comienzo de la experiencia. (Levinas, 2002, p. 116)

\section{Bibliografía}

Aranguren, J. (1998). Ética. Barcelona: Ediciones Altaya. S.A.

Banks, S. (1997). Ética y Valores en el Trabajo Social. Barcelona: Ediciones Paidós Ibérica.

Bellver, V. (2004). ¿Existe una ética universal? Bioética y Derechos. Cuad. Bioét. Escuela de Derecho. Universidad de Valencia. http://aebioetica.org/revistas/2004/15/3/55/437.pdf

Bermejo, F. (2002). La Ética del Trabajo Social (Ética de las Profesiones). Editorial Descleé De Brouwer.

Bohm, D. (1997). Sobre el diálogo. Barcelona: Editorial Kairós S.A.

Bohm, D. (1998). La totalidad y el orden implicado. Barcelona: Editorial Kairós S.A.

Cabrera, J. (2017). Organizaciones duales: Jerarquía y Redarquía. Recuperado de https://telos.fundaciontelefonica.com/formacion-organizaciones-duales-jerarquia-y-redarquia/

Cortina, A. (2017). Ética de las fundaciones, tiempos de corresponsabilidad. Boletín de Estudios Económicos, XXII(220), 5-22). Recuperado de https://www.academia.edu/40105458

Foucault, M. (2000). Defender la sociedad. Buenos Aires, Argentina: Fondo de Cultura Económica.

García, M. (2021) El horizonte interdisciplinario, una apuesta disidente. Estudios. Utopías y Praxis Latinoamericana, 26(94), 15-3617. Recuperado de https://dialnet.unirioja.es/servlet/ articulo? codigo $=8040419$

Habermas, J. (1987). Teoría de la acción comunicativa, I. Buenos Aires, Argentina: Editorial Taurus. 
Habermas, J. (2000). Aclaraciones a la ética del discurso. Madrid: Editorial Trotta.

Han, B. (2015). El aroma del tiempo. Barcelona: Editorial Herder.

Hernández, C. y López, J. (2002). Disciplinas. Bogotá, Colombia: Instituto colombiano para el fomento de la educación superior ICFES.

Hortal, A. (2002). Ética general de las profesiones. Bilbao: Editorial Descleé De Brouwer.

Levinas, E. (2002). Totalidad e Infinito. Ensayo sobre la exterioridad. Salamanca, España: Ediciones Sígueme.

Martínez, H. (2020). Una subjetividad infinita: hacia una comprensión teleológica de la conciencia desde la fenomenología levinasiana. Revista de Filosofía Dianoia, 65(84), 135166. Recuperado de https://dialnet.unirioja.es/servlet/ articulo? codigo $=7449381$

Morín, E. (1995). Introducción al pensamiento complejo. Editorial Gedisa.

Pérez de la Fuente, O. (2019). Presentación. Sobre alteridad. Revista Interdisciplinar de Estudios Histórico-Jurídicos, Luz Fugit, (22), 9-13. Recuperado de https://dialnet.unirioja.es/servlet/articulo?codigo $=7191774$

Rodríguez, R., Carranza, P., Bulgarelli, R., Ulate, Sy Camacho, M. (2020). El trabajo interdisciplinario de los equipos base del proyecto pedagógico para las personas menores de edad en albergues del Patronato Nacional de Infancia. Revista electrónica Educare, 24(3), 1-23. Recuperado de https://www.revistas.una. ac.cr/index.php/EDUCARE/article/view/11203

Solana, J. (2016). Trabajo Social, complejidad e interdisciplinariedad: una síntesis de algunos planteamientos en España e Hispanoamérica. Universidad de Jaén. Recuperado de: https:// publicaciones.unirioja.es/catalogo/online/CIFETS_2016/ Monografia/pdf/TC372.pdf 